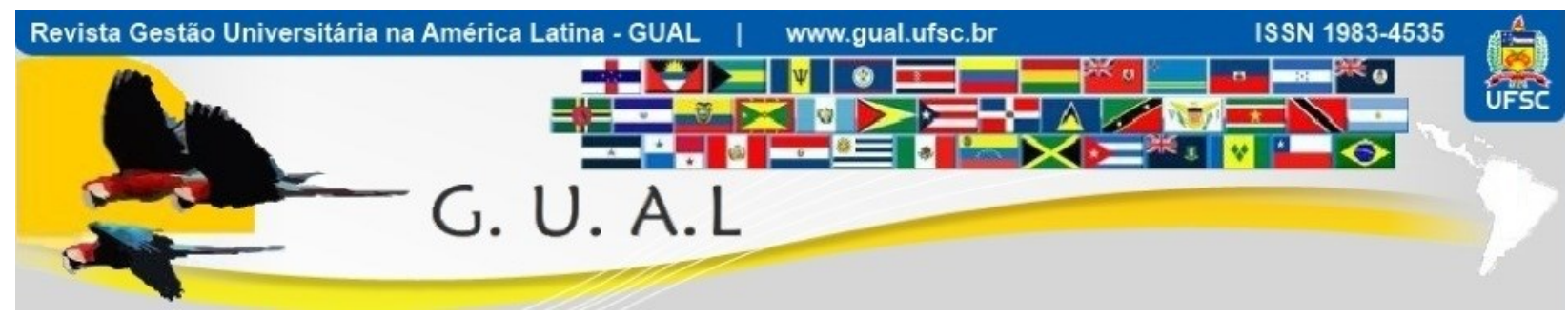

DOI: http://dx.doi.org/10.5007/1983-4535.2019v12n2p24

\title{
ESTRATÉGIAS APLICADAS NO ENSINO DA CONTABILIDADE: EVIDÊNCIAS DOS PLANOS DE ENSINO DE UMA UNIVERSIDADE PÚBLICA
}

\section{ADOPTION OF TEACHING STRATEGIES IN ACCOUNTING EDUCATION: EVIDENCE BASED ON LESSON PLANS ANALYSIS FROM A PUBLIC BRAZILIAN UNIVERSITY}

\author{
Leandro Marques, Mestre \\ https://orcid.org/0000-0003-0763-2302 \\ leandromarques@hotmail.com \\ Faculdade La Salle | Departamento de Ciências Contábeis \\ Lucas do Rio Verde | Mato Grosso do Sul | Brasil
}

Vania Tanira Biavatti, Doutora https://orcid.org/0000-0003-1564-2674 vania@hprada.com.br

Universidade Regional de Blumenau | Programa de Pós-Graduação em Ciências Contábeis Blumenau | Santa Catarina | Brasil

Recebido em 19/setembro/2017

Aprovado em 20/dezembro/2018

Publicado em 02/maio/2019

Sistema de Avaliação: Double Blind Review 


\title{
RESUMO
}

Este estudo objetivou identificar as estratégias de ensino que são aplicadas com maior frequência no Curso de Graduação em Ciências Contábeis nas disciplinas oferecidas por um curso vinculado a uma Universidade Catarinense. Para tanto foi conduzida uma pesquisa descritiva, com abordagem quantitativa, realizada por meio da análise documental dos planos de ensino da instituição. Foram analisados 614 planos de ensino, compreendendo um lapso temporal de dezesseis semestres. Os resultados demonstraram que as estratégias mais empregadas pelos docentes foram: exercícios, aulas expositivas, aulas expositivas dialogadas, estudo de texto, seminário, discussão e debate e caso de estudo. Também se verificou que os recursos didáticos mais utilizados são o projetor multimídia e o quadro. Pôde-se constatar que há diferenças de utilização de estratégias de acordo com o núcleo de conteúdo da disciplina, sendo que os planos de ensino do núcleo de formação básica foram os que apresentaram estratégias mais variadas, seguido pelas disciplinas da área gerencial. Constatou-se, ainda, diferenças de utilização de estratégia de acordo com a titulação do professor que ministra a disciplina. No entanto, infere-se que o grau de titulação do professor não interfere necessariamente no uso de estratégias de ensino variadas, visto que professor com doutorado acabaram apresentando menor repertório de estratégias declaradas.

Palavras-chave: Estratégias de Ensino. Recursos Didáticos. Planos de Ensino.

\begin{abstract}
This study aimed to identify the teaching strategies that are applied most frequently in Accounting Graduation from a Public University from Santa Catarina, in the South Region of Brazil. We adopted the descriptive research as research methodology, with quantitative approach based on the documental analysis of courses' lesson plans. We analyzed 614 lesson plans, referring to a period of sixteen semesters. The most frequently strategies were: exercises, lectures, dialoguing lectures, readings, seminars, discussion and debate and cases. We also verified that the most frequently didactic resources were data-show and blackboard. We find that lesson plans from basic courses showed several strategies when compared to other subjects. Finally, there was found differences in use of strategy according to the degree level of the professor teaching the course. Nevertheless, it is inferred that the teacher's academic degree does not necessarily interfere in the adoption of varied teaching strategy, since teachers with doctorate ended up adopting a smaller repertoire of declared strategies.
\end{abstract}

Keywords: Teaching Strategies. Didactic Resources. Lesson Plan. 


\section{INTRODUÇÃO}

As diversas mudanças ocorridas no cenário contábil nacional, em função da convergência às normas internacionais de contabilidade, da expansão das vagas no ensino superior e do aumento do número de pós-graduações stricto sensu em Ciências Contábeis acarretaram em grandes transformações no ensino da contabilidade (MIRANDA, CASA NOVA \& CORNACHIONE JR., 2013).

Especialmente em relação à harmonização das normas brasileiras com as normas internacionais de contabilidade, torna-se necessário que o contador desenvolva competências e habilidades para compreender, interpretar, julgar e aplicar as normas, que agora são baseadas em princípios e não mais em regras (OLIVEIRA et al., 2013). Neste novo cenário, para ministrar aulas com sucesso, é preciso que o professor possua, adicionalmente aos conhecimentos técnicos de contabilidade, conhecimento de mercado, multidisciplinaridade e didática, além de se fazer necessário que domine estratégias de ensino que tornem sua aula mais atraente e produtiva (HERNANDES, PELEIAS \& BARNALHO, 2006).

Marion e Marion (2006) salientam que se pode ser mais bem-sucedido no processo de ensino-aprendizagem quando utilizasse de métodos para ensinar. Os autores ainda apontam que um maior benefício pode ser alcançado pelos estudantes quando os professores usam formas e procedimentos adequados no seu ensino.

De forma semelhante, Palma e Queiroz (2006) comentam que a integração entre o currículo, os conteúdos, as disciplinas e as estratégias de ensino permitem ao professor dinamizar seu trabalho em sala de aula, além de facilitar o processo de ensino aprendizagem. Além disso, Bordenave e Pereira (2002) afirmam que a escolha adequada dos métodos de ensino é uma etapa importante da profissão para o docente moderno, visto que devem ser consonantes com os objetivos educacionais, com os conteúdos da matéria e com o perfil dos estudantes.

Assim, o docente deve variar as estratégias de ensino empregadas, tendo sempre em mãos estratégias diferenciadas entre si, para usos alternativos, conforme a ocasião, a maturidade e a formação prévia dos ouvintes e de acordo com o ambiente em que a aula está sendo ministrada (HERNANDES, PELEIAS \& BARNALHO, 2006).

Destarte, diversos estudos vêm sendo realizados com o intuito de conhecer e investigar as técnicas e estratégias adotadas pelos docentes no ensino da contabilidade, sendo que algumas destas têm demostrado que há maior predominância de técnicas tradicionais de 
ensino, tais como aula expositiva, em que o professor é o centro do processo de ensinoaprendizagem (TEODORO et al., 2011; MIRANDA, LEAL \& CASA NOVA, 2012; PASSOS \& MARTINS, 2012; MAZZIONE, 2013; LEAL \& BORGES, 2014; SILVA et al., 2014).

Estes resultados das pesquisas ensejam uma reflexão sobre as estratégias adotadas no ensino da contabilidade e a necessidade de desenvolvimento de novas habilidades no contador frente à convergência as normas internacionais de contabilidade, visto que, de acordo com Leal e Cornachione Jr. (2006), as técnicas tradicionais condicionam o aluno a uma posição passiva no processo de ensino-aprendizagem, não despertando um espírito crítico e participativo.

Partindo disso, emerge a questão problema a ser investigada: Quais as estratégias de ensino mais frequentemente declaradas nos planos de ensino pelos docentes do curso de Graduação em Ciências Contábeis? Desta maneira, o objetivo da presente pesquisa é identificar as estratégias de ensino que são declaradas com maior frequência nas disciplinas do Curso de Graduação em Ciências Contábeis vinculado a uma Universidade Catarinense.

A investigação e discussão sobre as estratégias de ensino adotadas no curso de Ciências Contábeis torna-se relevante pois, conforme comentam Petrucci e Batiston (2006), o conhecimento e a escolha da estratégia de ensino contribuem de forma decisiva para o trabalho docente, exercendo grande influência nos resultados obtidos pelos estudantes na avaliação da aprendizagem. Assim, a identificação das estratégias declaradas nos planos de ensino permite uma reflexão acerca da aplicabilidade de tais estratégias e da necessidade de se utilizarem estratégias diferenciadas daquelas usadas habitualmente.

Luckesi remete ainda para uma série de reflexões acerca das estratégias de ensino utilizadas pelo professor: se as estratégias possuem articulação coerente com a proposta pedagógica, se a escolha é feita em função da modernidade ou da facilidade da estratégia ou, ainda, se a escolha não é baseada em nenhum critério específico. Deste modo, este trabalho pode auxiliar no sentido de proporcionar que os professores ponderem a respeito dos critérios utilizados para a escolha das estratégias.

Além disso, conforme ressaltam Miranda et al. (2013), é preciso que ações sejam tomadas para fortalecer os estudos sobre educação contábil no cenário brasileiro, por meio de investigações de problemas relacionados ao ensino da contabilidade. Este estudo, junta-se assim à outras pesquisas que compõe o corpo de investigações sobre o ensino da 
Contabilidade no Brasil (LEAL \& CORNACHIONE JR.; 2006; TEODORO et al., 2011; MIRANDA, LEAL \& CASA NOVA, 2012; PASSOS \& MARTINS, 2012; MAZZIONE, 2013; NGANGA et al., 2013; LEAL, BORGES, 2014; SILVA et al., 2014).

O restante do artigo é dividido nas seguintes partes: referencial teórico, em que são apresentados as estratégias de ensino e os estudos correlatos sobre o tema; procedimentos metodológicos, em que se apresentam os meios para a consecução da pesquisa; análise dos dados, em que são apresentados e analisados os dados da pesquisa; e conclusão. Com base nos resultados tem-se que as estratégias mais empregadas pelos docentes foram: exercícios, aulas expositivas, aulas expositivas dialogadas, estudo de texto, seminário, discussão e debate e caso de estudo. Constatou-se que há diferenças de utilização de estratégias de acordo com o núcleo de conteúdo da disciplina e de acordo com a titulação do professor que ministra a disciplina.

\section{REFERENCIAL TEÓRICO}

\subsection{O QUE SÃO ESTRATÉGIAS DE ENSINO?}

O professor de ensino superior necessita tomar uma série de decisões em relação à sua atuação, tais como, a definição dos objetivos a serem alcançados pelos estudantes na disciplina, o conteúdo programático a ser ministrado no curso, as estratégias e recursos adotados e os critérios de avaliação. Estas decisões constituem o processo de planejamento de ensino, fator essencial para o êxito do trabalho docente (GIL, 2005). Masetto (2003, p. 176) define o planejamento de uma disciplina como a "organização ou sistematização das ações do professor e dos alunos tendo em vista a consecução dos objetivos de aprendizagem estabelecidos". Neste sentido, Leal (2005) destaca que o planejamento do ensino tem características particulares, pois lida com sujeitos que estão em processo de formação humana.

As decisões tomadas no processo de planejamento materializam-se em documentos normalmente denominados de planos. No caso do professor, as decisões são consolidadas em planos de ensino (GIL, 2005). Um plano de ensino pode ser definido como "um documento organizado de forma sequencial, respeitando os itens que o compõem, expressando, em todo o seu contexto, as decisões tomadas sobre a prática do professor” (MALUSÁ, 2003, p. 166).

No entanto, Masetto (2003) salienta que o plano, para ser eficiente, deve ser flexível e adaptável, visto que o planejamento traz consigo a característica da flexibilidade. Assim, o 
autor ainda comenta que o planejamento não pode ser considerado como uma camisa-de-força que restrinja a liberdade do professor. Não existe um modelo rígido que deva ser seguido na elaboração de um plano de ensino. Mas, todo plano deve conter numa sequência coerente os elementos considerados relevantes no processo de ensino aprendizagem (GIL, 2005). Masetto (2003) sugere que o plano de ensino contemple as seguintes informações: identificação, objetivos, ementa, conteúdo programático, técnicas, avaliação, bibliografia e cronograma.

No que tange às técnicas de ensino, Gil (2005) aponta que o termo mais utilizado para designar tal sessão nos planos de ensino é "estratégia". Porém o autor salienta que expressões como métodos de ensino, métodos didáticos, técnicas pedagógicas e técnicas de ensino também são utilizadas para nomear tal componente. Neste estudo optou-se por adotar o termo estratégias de ensino para designar os métodos utilizados pelos professores no processo de ensino-aprendizagem, uma vez que o termo estratégia parece ser mais abrangente do que os demais.

Petrucci e Batiston (2006) também empregam o termo estratégias de ensino pois, segundo os autores, o termo compreende tanto os procedimentos de ensino quanto os recursos pedagógicos. Para Martins (1993), os procedimentos de ensino compreendem as ações do professor em relação à organização do ensino, ao passo que os recursos pedagógicos abrangem "os elementos disponíveis no ambiente em que se realiza a aprendizagem. São exemplos as instalações da instituição, as apostilas, os livros, os vídeos e o mobiliário, dentre outros" (PETRUCCI \& BATISTON, 2006, p.264).

Existem, descritas na literatura, diversas estratégias que podem ser aplicadas no processo de ensino-aprendizagem. Entre elas, temos a aula expositiva, seminários, palestras, visitas técnicas, entre diversas outras. A aula expositiva é uma das mais antigas e tradicionais estratégias de ensino (PETRUCCI \& BATISTON, 2006). Pode ser descrita como uma “comunicação verbal estruturada, utilizada pelos professores com o objetivo de transmitir determinados conteúdos aos alunos" (LOPES, 2002, p. 39).

A aula expositiva tem sido criticada por ser uma estratégia excessivamente passiva e tradicional que favorece aprendizagens do tipo receptiva (GODOY, 1997). Neste sentido, uma alternativa a aula expositiva tradicional pode ser a aula expositiva dialogada que conta com a participação ativa dos estudantes, que questionam, interpretam e discutem o objeto de estudo a partir do reconhecimento e do confronto com a realidade (ANASTASIOU \& ALVES, 2004). 


\section{ESTRATÉGIAS APLICADAS NO ENSINO DA CONTABILIDADE: EVIDÊNCIAS DOS PLANOS DE

Outra estratégia de ensino é o estudo dirigido que, de acordo com Marion e Marion (2006, p. 46), “consiste na orientação aos alunos de determinado conteúdo, observando a modalidade de percepção dos alunos que farão parte desse estudo para programar a atividade". Nesta estratégia o aprendizado decorre do esforço individual do estudante, sendo que o professor contribui apenas no sentido de indicar os melhores caminhos para a aprendizagem (PETRUCCI \& BATISTON, 2006).

Em relação à estratégia de discussão e debate, Marion e Marion (2006) afirmam que é bastante tradicional, pois sugere aos educandos a reflexão acerca de conhecimentos obtidos após uma leitura ou exposição. O objetivo principal do debate é permitir que o estudante expresse suas opiniões em público, apresentando ideias, reflexões, experiências e vivências, argumentando e defendendo suas próprias posições (MASETTO, 2003).

O seminário, por sua vez, destina-se ao estudo de diversos assuntos de um mesmo campo de conhecimentos, por meio da apresentação de tais assuntos por especialistas ou pessoas adequadamente preparadas para tal (NERICI, 1990). Esta estratégia "permite ao aluno desenvolver sua capacidade de pesquisa, de produção de conhecimento, de comunicação, de organização e fundamentação de ideias, de elaboração de relatório de pesquisa, de fazer inferências e produzir conhecimento em equipe, de forma coletiva” (MASETTO, 2003).

Quanto ao caso de ensino, Petrucci e Batiston (2006, p.283) comentam que tal estratégia "consiste em propor à classe um problema real relacionado ao assunto que está sendo estudado". Esta abordagem permite desenvolver a capacidade analítica do estudante, que buscará soluções para o problema relatado no caso (MARION \& MARION, 2006). Na área de negócios, o caso de estudo possui relevância, pois permite estabelecer conexões entre a teoria estudada em sala e a prática profissional (MIRANDA, LEAL \& CASA NOVA, 2012).

Além das estratégias de ensino supramencionadas, a literatura apresenta diversas outras que podem ser utilizadas pelo professor no processo de ensino-aprendizagem. Para cada estratégia de ensino, pode-se escolher alguns recursos didáticos, que auxiliarão na execução da estratégia escolhida (MARION; MARION, 2006). Petrucci e Batiston (2006) explicam que a tecnologia vem sendo cada vez mais utilizada pelos professores como um recurso no processo de ensino-aprendizagem. Os autores ainda mencionam que os recursos audiovisuais estão presentes em todas as instituições de ensino do país, sendo que alguns possuem maior utilização que outros. Como recursos audiovisuais que podem ser utilizados 
no processo de ensino-aprendizagem encontram-se o quadro, o retroprojetor, o flipchart, o DVD, o projetor multimídia e o computador.

O fato é que, conforme aduz Nérici (1997), não há técnicas velhas ou novas, superadas ou atuais, todas são válidas, uma vez que sejam utilizadas de modo ativo, permitindo aos estudantes refletir e desenvolver o senso crítico. Em relação às estratégias utilizadas no ensino da Contabilidade, alguns estudos já foram empreendidos com o intuito de analisar quais as estratégias empregadas pelos docentes. A seguir apresentam-se alguns destes estudos, destacando seus achados e contribuições.

\subsection{ESTUDOS CORRELATOS}

O estudo conduzido por Leal e Cornachione Jr. (2006) buscou verificar a relação entre a utilização da aula expositiva e a qualidade do estudante que se forma nos cursos de Ciências Contábeis no Brasil. Para tal, os autores realizaram uma pesquisa empírico-bibliográfica, por meio de entrevistas com professores e estudantes do curso de Ciências Contábeis da FEA/USP e, também, de dados relativos ao Exame Nacional de Cursos (provão) promovido pelo INEP-MEC, nos anos de 2002 e 2003. Como resultado, identificaram que o desenvolvimento de competências de formação foi maior pelos contadores recém-formados que foram submetidos ao método de aula expositiva combinado com participação, do que pelos que tiveram apenas o método de aula expositiva.

Já o estudo realizado por Teodoro et al. (2011) teve por objetivo identificar as estratégias de ensino-aprendizagem utilizadas nos cursos de licenciatura em Pedagogia e bacharelado em Ciências Contábeis na Universidade Federal do Paraná (UFPR) e Universidade Estadual de Maringá (UEM) na percepção dos discentes. A coleta dos dados ocorreu por meio de questionários aplicados aos estudantes, sendo que se obteve 224 respostas válidas na UEM e 225, na UFPR. Os autores verificaram que o ensino, nas duas Universidades, caracteriza-se por aulas expositivas e resolução de exercícios, com eventuais soluções de problemas e com utilização, principalmente, de projetor multimídia, e-mail e livros didáticos.

O estudo de Miranda, Leal e Casa Nova (2012) buscou identificar quais as técnicas de ensino que proporcionam maior significado aos conteúdos ensinados no curso de Ciências Contábeis, na percepção dos estudantes e professores. Para tanto, realizou-se uma pesquisa de levantamento com 151 alunos e 18 docentes da Universidade Federal de Uberlândia (UFU), 
sendo que os dados coletados foram analisados por meio de estatística descritiva e análise de cluster. Verificou-se que as técnicas mais aplicadas e consideradas mais significativas, na concepção tanto dos docentes quanto dos discentes, são aquelas consideradas tradicionais (cluster 1): aula expositiva, trabalhos em grupo/seminário, caso de estudo, aulas práticas em laboratório, discussões/debates/grupos de oposição, leitura/estudo dirigido e ensino com pesquisa. Ao passo que técnicas "não tradicionais" (cluster 2), como aprendizagem experiencial/estágio, visitas técnicas e excursões, formulação de questões, jogos e simulações, simpósio, ensino com projeto, Problem Based Learning, diálogos sucessivos, GV e GO, dramatização e painel integrado, foram as menos aplicadas e consideradas menos significativas.

Passos e Martins (2012) realizaram um estudo semelhante, cujo objetivo foi identificar e analisar os métodos, técnicas e recursos de ensino utilizados pelos professores de contabilidade de quatro Instituições de Ensino Superior (IESs). Os dados da pesquisa foram coletados por meio de entrevistas semiestruturadas e questionários, sendo que a amostra final foi composta por 20 docentes de instituições localizadas na cidade de São Paulo. Constatou-se que a aula expositiva, seguida de exercícios, é a técnica mais comum entre os docentes, sendo também identificada a ocorrência de seminários, caso de estudos e palestras. Quanto aos recursos utilizados, destacaram-se a lousa e as transparências, seguidas por datashow, vídeo, laboratório de informática, e-mail e conteúdos disponíveis na internet.

Mazzione (2013) estudou as estratégias de ensino-aprendizagem mais significativas na visão dos alunos e as mais utilizadas pelos professores que ministram disciplinas de formação específica do curso de Ciências Contábeis da Universidade Comunitária Regional de Chapecó. Para tanto, o autor aplicou um questionário a nove docentes e 83 discentes da universidade. Os resultados demonstraram que, tanto na visão dos professores quanto na visão dos alunos, a aula expositiva é a estratégia mais utilizada e a resolução de exercícios é a estratégia mais bem-sucedida. Em relação aos recursos utilizados constatou-se que, na concepção dos alunos, o datashow é o recurso mais utilizado. Ao passo que, na percepção dos docentes, é o quadro branco.

De maneira semelhante, Nganga et al. (2013) objetivaram identificar quais as principais estratégias de ensino adotadas na educação contábil nas disciplinas da área de Contabilidade Gerencial que proporcionam maior eficácia ao aprendizado, na percepção dos professores. Participaram do estudo 41 docentes de Instituições de Ensino Superior do estado 
de Minas Gerais, que lecionam ou lecionaram disciplinas da área de Contabilidade Gerencial. Por meio de uma análise de cluster foi possível identificar que as estratégias aula expositiva, discussões/debates/grupos de oposição, ensino com pesquisa, jogos/simulações, leitura/estudo dirigido, caso de estudo, trabalhos em grupo/seminário, visitas técnicas e aulas práticas e de laboratório foram as mais utilizadas e mais significativas. Também pôde-se constatar que, para os docentes participantes da pesquisa, as estratégias aplicadas no ensino da contabilidade gerencial não divergem daquelas que eles consideram mais eficazes para o aprendizado.

A pesquisa de Leal e Borges (2014) teve por objetivo identificar as estratégias de ensino aplicadas no curso de graduação em Ciências Contábeis de uma IES pública brasileira. Os autores analisaram 335 planos de ensino, do período de 2008 a 2012, dos quais pôde-se constatar que as estratégias mais empregadas pelos docentes foram aulas expositivas, aplicação de exercícios, caso de estudo, debates e seminários estudos dirigidos, trabalhos de pesquisa e dinâmicas de grupo. Os resultados também apontaram que existem diferenças significantes entre as proporções de utilização das estratégias de ensino analisadas, quando comparadas por áreas de conhecimento.

Por fim, o estudo de Silva et al. (2014) buscou identificar a concepção educacional utilizada em uma IES pública de Salvador. A amostra do estudo compreendeu 210 alunos que responderam a um questionário. Os autores verificaram que estratégias tradicionais, como aula expositiva e seminário, são as mais utilizadas pelos professores, com pouca utilização de debates, PBL e estudos de caso. Verificou-se, ainda, que o projetor multimídia e o retroprojetor são os recursos mais empregados pelos professores para ministrar as aulas.

\section{PROCEDIMENTOS METODOLÓGICOS}

A presente pesquisa caracteriza-se, quanto aos objetivos, como descritiva. Quanto aos procedimentos, caracteriza-se como uma pesquisa documental, uma vez que se utiliza da análise dos planos de ensino. Em relação à abordagem, constitui-se em pesquisa quantitativa, pois emprega técnicas estatísticas no tratamento dos dados coletados.

Os planos de ensino analisados são de uma instituição de ensino superior pública do estado de Santa Catariana. A instituição oferece o curso de Ciências Contábeis há oito anos, no período noturno. Os planos de ensino das disciplinas ofertadas são disponibilizados em sua página eletrônica, sendo de livre acesso. Os planos de ensino analisados contemplaram 16 
semestres, em um período que vai de 2007 a 2015 compreendendo todos os planos de ensino disponíveis desde o início do curso e totalizando, assim, 622 documentos.

A primeira parte da análise consistiu em ler todos os planos de ensino, especialmente o tópico "metodologia proposta", pois é nesta seção que os docentes informam as estratégias de ensino adotadas na condução da disciplina. Neste momento as estratégias encontradas nos planos foram transcritas em uma planilha eletrônica, especificando à que matéria pertenciam, qual o ano e semestre correspondente, à que fase do curso a disciplina pertencia, bem como o nome do docente que lecionou a disciplina.

Também foram coletadas informações referentes ao núcleo de conteúdo da disciplina, sendo que estas se encontram dispostas em três núcleos: formação básica, formação profissional e formação teórico-prática. As disciplinas do núcleo de formação profissional foram, ainda, subdivididas nos seguintes grupos: contabilidade gerencial, contabilidade financeira, contabilidade pública/tributária e outras. As disciplinas da área de contabilidade gerencial foram classificadas de acordo com os conteúdos contemplados em suas ementas, adotando-se o mesmo critério do estudo de Macêdo et al. (2014).

Por fim, consultou-se o currículo Lattes dos docentes das disciplinas, a fim de identificar qual sua titulação. Este procedimento foi necessário, pois tal informação não estava disponível nos planos de ensino. Na Tabela 1, apresenta-se a composição da amostra.

Tabela 1 Caracterização da Amostra

\begin{tabular}{lccccccccccccccccccc}
\hline Ano & $\mathbf{2 0 0 7}$ & $\mathbf{2 0 0 8}$ & $\mathbf{2 0 0 9}$ & $\mathbf{2 0 1 0}$ & $\mathbf{2 0 1 1}$ & $\mathbf{2 0 1 2}$ & $\mathbf{2 0 1 3}$ & $\mathbf{2 0 1 4}$ & $\mathbf{2 0 1 5}$ & Total \\
\hline Semestre & 2 & 1 & 2 & 1 & 2 & 1 & 2 & 1 & 2 & 1 & 2 & 1 & 2 & 1 & 2 & 1 & $\mathbf{1 6}$ \\
Disponíveis & 7 & 12 & 18 & 27 & 31 & 41 & 47 & 51 & 52 & 49 & 52 & 49 & 53 & 47 & 45 & 41 & $\mathbf{6 2 2}$ \\
Com Estratégia & 7 & 12 & 17 & 27 & 30 & 40 & 46 & 50 & 50 & 48 & 52 & 49 & 53 & 47 & 45 & 41 & $\mathbf{6 1 4}$ \\
\hline
\end{tabular}

Fonte: dados da pesquisa.

Pode-se observar na Tabela 1, que nem todos os planos de ensino apresentaram o tópico "metodologia proposta". Os planos de ensino sem a metodologia proposta foram excluídos da amostra inicial de estudo, uma vez que não apresentavam as informações necessárias à análise, totalizando, assim, uma amostra de 614 planos de ensino.

Após a tabulação dos dados coletados, as estratégias propostas nos planos de ensino foram classificadas de acordo com as estratégias apresentadas na revisão de literatura deste artigo. Em seguida os dados foram analisados por meio da estatística descritiva. Tal análise é apresentada no tópico a seguir. 


\section{ANÁLISE DOS DADOS}

\subsection{ESTRATÉGIA DE ENSINO MAIS RECORRENTES}

Como mencionado anteriormente, foram analisados 614 planos de ensino, compreendendo um lapso temporal de 16 semestres. As disciplinas foram, então, classificadas de acordo com o núcleo de conteúdo a que pertenciam. Na Tabela 2 apresenta-se a quantidade total de planos de ensino por núcleo de conteúdo.

Tabela 2 Planos de Ensino por Núcleo de Conteúdo

\begin{tabular}{|c|c|c|c|c|c|c|c|}
\hline \multirow[b]{2}{*}{ Área } & \multirow{2}{*}{$\begin{array}{c}\text { Formação } \\
\text { Básica }\end{array}$} & \multicolumn{4}{|c|}{ Formação Profissional } & \multirow{2}{*}{$\begin{array}{c}\text { Formação } \\
\text { Teórico- } \\
\text { prática }\end{array}$} & \multirow[b]{2}{*}{ Total } \\
\hline & & Financeira & Gerencial & Pública/Tributária & $\begin{array}{c}\text { Outras } \\
\text { Áreas }\end{array}$ & & \\
\hline Planos de Ensino & 263 & 126 & 66 & 36 & 72 & 51 & 614 \\
\hline
\end{tabular}

Fonte: dados da pesquisa

Como se pode observar na Tabela 2 a maior parte dos planos de ensino analisados corresponde às disciplinas do núcleo de formação profissional, sendo que, nesta categoria, as disciplinas ligadas à área financeira predominaram, seguidas por disciplinas da área gerencial, de outras áreas e, finalmente, da área pública/tributária. Encontraram-se, ainda, 263 planos de ensino no núcleo de formação básica e 51 planos de ensino de disciplinas de formação teórico-prática.

Em relação às estratégias identificadas, verificou-se que 23 tipos de estratégias diferentes foram declarados nos planos de ensino analisados. A aula expositiva apareceu em todos os planos de ensino (614), convergindo assim aos achados de Miranda, Leal e Casa Nova (2012), Passos e Martins (2012), Mazzione (2013), Nganga et al. (2013), Leal e Borges (2014) e Silva et al. (2014) e corroborando a fala de Gil (2005) de que esta estratégia ainda é muito empregada nas universidades.

Entretanto, notou-se que alguns professores declararam utilizar a modalidade de aula expositiva dialogada. Desta forma, optou-se por dividir na análise dos dados os planos de ensino que apresentaram apenas a modalidade aula expositiva $(52,77 \%)$ daqueles que apresentaram a modalidade aula expositiva dialogada (47,23\%). Na Tabela 3 apresentam-se as estratégias observadas nos planos de ensino analisados, bem como a quantidade de planos em que foram declaradas e a proporção correspondente. 


\section{ESTRATÉGIAS APLICADAS NO ENSINO DA CONTABILIDADE: EVIDÊNCIAS DOS PLANOS DE ENSINO DE UMA UNIVERSIDADE PÚBLICA \\ DOI: http://dx.doi.org/10.5007/1983-4535.2019v12n2p24}

Tabela 3 Estratégias de ensino identificadas

\begin{tabular}{lcc|lcc}
\hline Estratégias & $\mathbf{N}^{\mathbf{0}}$ & $\mathbf{\%}$ & Estratégias & $\mathbf{N}^{\mathbf{0}}$ & $\mathbf{\%}$ \\
\hline Exercícios & 447 & $72,80 \%$ & Palestras & 11 & $1,79 \%$ \\
Aula Expositiva & 324 & $52,77 \%$ & Dinâmica & 11 & $1,79 \%$ \\
Aula Expositiva Dialogada & 290 & $47,23 \%$ & Ensino com projeto & 8 & $1,30 \%$ \\
Estudo de Texto & 218 & $35,50 \%$ & Dramatização & 7 & $1,14 \%$ \\
Seminário & 149 & $24,27 \%$ & Jogos de empresa & 7 & $1,14 \%$ \\
Discussão e Debate & 147 & $23,94 \%$ & Painel & 2 & $0,33 \%$ \\
Caso de Estudo & 147 & $23,94 \%$ & Júri simulado & 2 & $0,33 \%$ \\
Ensino com pesquisa & 135 & $21,99 \%$ & Estudo de Campo & 1 & $0,16 \%$ \\
Aula Prática e em Laboratório & 99 & $16,12 \%$ & Grupos de Verbalização e de Observação & 0 & $0,00 \%$ \\
Projeção de vídeos & 78 & $12,70 \%$ & Aprendizagem baseada em problema (PBL) & 0 & $0,00 \%$ \\
Ensino à Distância & 52 & $8,47 \%$ & Simpósio & 0 & $0,00 \%$ \\
Produção Textual & 49 & $7,98 \%$ & Aprendizagem Experiencial/Estágio & 0 & $0,00 \%$ \\
Explicação por parte do aluno & 34 & $5,54 \%$ & Diálogos sucessivos & 0 & $0,00 \%$ \\
Exposções e Visitas técnicas & 28 & $4,56 \%$ & Formulação de questões & 0 & $0,00 \%$ \\
Estudo Dirigido & 14 & $2,28 \%$ & & \\
\hline
\end{tabular}

Fonte: dados da pesquisa

Observa-se, na Tabela 3, que a quantidade de professores que declararam utilizar a modalidade aula expositiva dialogada $(47,23 \%)$ é inferior à quantidade de professores que utilizam a aula expositiva (52,77\%). Este resultado diverge do encontrado por Leal e Cornachione Jr. (2006), que identificaram um aumento das aulas expositivas com a participação dos alunos.

Este achado remete a uma reflexão sobre a aula expositiva, pois conforme afirmam Petrucci e Batiston (2006, p. 269), "a participação ativa do discente é condição essencial para um aprendizado de qualidade". Assim, talvez um maior benefício fosse alcançado, tanto por docentes, quanto por discentes, se ao invés do professor optar pelo método da preleção, ou seja, aulas expositivas, este optasse pela aula expositiva dialogada. Tal fato já foi constatado no estudo de Leal e Cornachione Jr. (2006), demonstrando que o desenvolvimento de competências em contadores recém-formados é maior naqueles que foram submetidos à aula expositiva combinada com participação.

Estas evidências indicam a necessidade de que os professores repensem suas aulas expositivas, não apenas na instituição de ensino analisada neste estudo, mas, também, em outras instituições, para que esta contemple uma maior inserção e participação do aluno.

Outra estratégia bastante utilizada, aparecendo em 72,80\% dos planos analisados foi a de exercícios. Tal estratégia também foi identificada nos estudos de Teodoro et al. (2011), Passos e Martins (2012) e Leal e Borges (2014). Normalmente, a aplicação de exercícios ocorre logo após a aula expositiva, como forma de reforçar o conteúdo ministrado (MARION \& MARION, 2006). 


\section{ESTRATÉGIAS APLICADAS NO ENSINO DA CONTABILIDADE: EVIDÊNCIAS DOS PLANOS DE

Na pesquisa de Mazzione (2013) a aplicação de exercícios apresentou-se como a estratégia mais bem sucedida, tanto na visão dos docentes quanto na visão dos discentes. Deste modo, pode-se perceber que os professores da instituição investigada nesta pesquisa utilizam muito esta estratégia para a consecução dos objetivos declarados no plano de ensino.

A quarta estratégia mais recorrente nos planos de ensino analisados nesta pesquisa foi a de estudo de texto, aparecendo em 35,50\% dos planos de ensino. Destaca-se que, dentre os estudos correlatos, apenas o de Teodoro et al. (2011) identificou tal estratégia. De acordo com Grillo e Freitas (2008), o estudo de texto possibilita ao aluno entrar em contato com diversos autores e com produções teóricas diversas, publicadas ou apresentadas em eventos científicos.

Em relação ao seminário, pode-se observar na Tabela 3 que esta foi a quinta estratégia mais frequente, presente em $24,27 \%$ dos planos de ensino analisados. A utilização de seminários também foi identificada nas pesquisas de Miranda, Leal e Casa Nova (2012), Passos e Martins (2012), Nganga et al. (2013), Leal e Borges (2014) e Silva et al. (2014). Contudo, há que se olhar este resultado com cautela, visto que Balzan (1995) alerta para o fato de que muitos professores confundem o seminário com a aula expositiva dada pelos alunos, em que cada um apresenta uma parte do trabalho sem haver integração e envolvimento de todos os participantes.

Posteriormente, as estratégias de discussão e debate e caso de estudo aparecem em sexto lugar, ocorrendo com a mesma frequência $(23,94 \%)$. O debate foi também identificado nas pesquisas de Miranda, Leal e Casa Nova (2012), Nganga et al. (2013) e Leal e Borges (2014). Em relação ao caso de estudo, verificou-se que, assim como a discussão e debate, sua utilização é moderada, aparecendo em menos de um quarto dos planos analisados. Este resultado converge aos achados de Silva et al. (2014), que relataram pouca utilização desta estratégia de ensino. Porém, diverge dos estudos de Miranda, Leal e Casa Nova (2012) e Nganga et al. (2013) que encontraram altos índices de utilização desta estratégia.

Além das estratégias acima comentadas, pode-se observar na Tabela 3 que diversas outras foram identificadas. Dentre as estratégias observadas constatou-se que seis delas não haviam sido contempladas na revisão de literatura, sendo: projeção de vídeos, ensino à distância, produção textual, explicação por parte do aluno, dinâmica e estudo de campo.

Destaca-se que, assim como no estudo de Miranda, Leal e Casa Nova (2012), as estratégias de exposições e visitas técnicas, jogos de empresas, ensino com projeto, 
dramatização e painel foram pouco recorrentes, aparecendo em menos de $5 \%$ dos planos de ensino analisados.

Somado a isso, ressalta-se que algumas das estratégias encontradas na revisão de literatura não foram identificadas no material analisado. Tais estratégias foram: grupos de verbalização e observação, aprendizagem baseada em problema, simpósio, aprendizagem experiencial/estágio, diálogos sucessivos e formulação de questões. Isso denota que os professores do curso de graduação em Ciências Contábeis possuem pouca adesão às estratégias de ensino menos convencionais, dando preferência àquelas em que o aluno ocupa uma posição passiva no processo de ensino-aprendizagem.

Este resultado aponta para uma necessidade observada por Miranda, Leal e Casa Nova (2012): a de que os professores busquem estratégias não tradicionais a fim de dinamizar suas aulas. O turno do curso de graduação em Ciências Contábeis da instituição cujos planos de ensino foram analisados é noturno. Assim, é normal que os estudantes venham para a aula cansados após um dia de serviço. Deste modo, a preleção pode não ser a estratégia mais adequada em determinadas situações, pois pode tornar a aula maçante e dispersar a atenção do estudante. Além disso, Petrucci e Batiston (2006) comentam que variar as estratégias pode contribuir para o sucesso do processo de ensino-aprendizagem.

Deve-se lembrar, porém, que a escolha de diferentes estratégias de ensino está limitada a fatores como o conhecimento e o domínio do professor sobre as técnicas, a carga horária de professores e estudantes e a estrutura da organização (BORDENAVE \& PEREIRA, 2002).

Em relação à estrutura, os recursos didáticos disponibilizados pela instituição de ensino são peça fundamental para a articulação de diferentes estratégias de ensino. Neste sentido, pôde-se observar que são poucos os professores que declaram os recursos no plano de ensino, visto que o recurso mais recorrente, o projetor multimídia, apareceu em menos de $50 \%$ dos planos de ensino analisados, conforme observa-se na Tabela 4, a seguir.

Tabela 4 Recursos identificados

\begin{tabular}{lcc|lcc}
\hline Recursos & $\mathbf{N}^{\mathbf{0}}$ & $\mathbf{\%}$ & Recursos & $\mathbf{N}^{\mathbf{0}}$ & $\mathbf{\%}$ \\
\hline Projetor Multimídia & 231 & $37,62 \%$ & Calculadora HP 12 & 36 & $5,86 \%$ \\
Quadro & 149 & $24,27 \%$ & Ambiente Virtual de Aprendizagem & 31 & $5,05 \%$ \\
Retroprojetor & 120 & $19,54 \%$ & Internet & 8 & $1,30 \%$ \\
Recursos Audiovisuais Não Especificados & 100 & $16,29 \%$ & Apostila & 7 & $1,14 \%$ \\
Computador & 96 & $15,64 \%$ & Flip Chart & 0 & $0,00 \%$ \\
Textos & 55 & $8,96 \%$ & Videocassete/DVD & 0 & $0,00 \%$ \\
Softwares & 45 & $7,33 \%$ & & & \\
\hline
\end{tabular}

Fonte: dados da pesquisa 


\section{ESTRATÉGIAS APLICADAS NO ENSINO DA CONTABILIDADE: EVIDÊNCIAS DOS PLANOS DE

Nota-se na Tabela 4 que, além do projetor multimídia, o quadro também é um recurso muito utilizado, aparecendo em 24,27\% dos 614 planos de ensino. Estes resultados convergem aos achados de Teodoro et al. (2011), Passos e Martins (2012) e Mazzione (2013). Foram também identificados como recursos didáticos o retroprojetor, computador, textos, softwares, calculadora HP 12C, ambiente virtual de aprendizagem, internet e apostila. Os recursos flipchart e videocassete/DVD não foram declarados em nenhum plano de ensino. Destaca-se que em $16,29 \%$ dos planos analisados não foi possível identificar qual era o recurso audiovisual, visto que o professor adotou uma denominação genérica.

Em relação à utilização da tecnologia do processo de ensino-aprendizagem deve-se ter em mente que a tecnologia não substitui o professor. Esta se constitui apenas em um instrumento para ser usado em algumas etapas do processo de ensino-aprendizagem e não deve ser adotada como estratégia única para um curso ou uma disciplina (PETRUCCI \& BATISTON, 2006).

Após se analisar as estratégias e recursos mais recorrentes nos planos de ensino das disciplinas do curso de graduação em Ciências Contábeis, procedeu-se a análise por núcleo de conteúdo da disciplina e, posteriormente, por titulação do professor. Os resultados dessas análises são apresentados no tópico relatado a seguir.

\subsection{ESTRATÉGIAS DE ENSINO POR NÚCLEO DE CONTEÚDO E POR TITULAÇÃO}

Uma etapa adicional da análise dos dados contemplou a identificação das estratégias de ensino por núcleo de conteúdo das disciplinas. Na Tabela 5, apresentam-se a frequência com que foram identificadas as estratégias de ensino em cada um dos núcleos de conteúdo.

Analisando-se a Tabela 5 pode-se verificar que a estratégia de aplicação de exercícios é uma das mais frequentes em todos os núcleos de conteúdo, visto que foi citada em mais de $50 \%$ dos planos de ensino de cada núcleo, resultado este que assemelha-se ao encontrado por Leal e Borges (2014), que também identificaram altos índices de aplicação de exercícios em todas as áreas de conhecimento que analisaram.

Em relação à aula expositiva, observa-se que a modalidade dialogada é mais recorrente nas disciplinas do núcleo de formação básica, do núcleo de formação teóricoprática e da área gerencial. $\mathrm{Na}$ área financeira, verifica-se que a aula expositiva foi apresentada na mesma quantidade de planos que a aula expositiva dialogada (63). Nas demais áreas houve predominância da aula expositiva em relação à aula expositiva dialogada. 
Tabela 5 Estratégias de ensino por Núcleo de Conteúdo

\begin{tabular}{|c|c|c|c|c|c|c|c|c|c|c|c|c|}
\hline \multirow{3}{*}{ Estratégias } & \multirow{2}{*}{\multicolumn{2}{|c|}{$\begin{array}{c}\text { Formação } \\
\text { Básica }\end{array}$}} & \multicolumn{8}{|c|}{ Formação Profissional } & \multirow{2}{*}{\multicolumn{2}{|c|}{$\begin{array}{c}\text { Formação } \\
\text { Teórico- } \\
\text { Pratica }\end{array}$}} \\
\hline & & & \multicolumn{2}{|c|}{ Financeira } & \multicolumn{2}{|c|}{ Gerencial } & \multicolumn{2}{|c|}{\begin{tabular}{|c|} 
Pública/ \\
Tributária
\end{tabular}} & \multicolumn{2}{|c|}{$\begin{array}{c}\text { Outras } \\
\text { Áreas }\end{array}$} & & \\
\hline & $\mathrm{Q}$ & $\%^{\mathrm{a}}$ & $\bar{Q}$ & $\%^{\mathrm{a}}$ & Q & $\%^{\mathrm{a}}$ & $\mathrm{Q}$ & $\%^{a}$ & $\mathrm{Q}$ & $\%^{\mathrm{a}}$ & $\mathrm{Q}$ & $\%^{\mathrm{a}}$ \\
\hline Exercícios & 135 & 51,33 & 123 & 97,62 & 55 & 83,33 & 29 & 80,56 & 59 & 81,94 & 46 & 90,20 \\
\hline Aula Expositiva & 127 & 48,29 & 63 & 50,00 & 29 & 43,94 & 33 & 91,67 & 50 & 69,44 & 22 & 43,14 \\
\hline Aula Expositiva Dialogada & 136 & 51,71 & 63 & 50,00 & 37 & 56,06 & 3 & 8,33 & 22 & 30,56 & 29 & 56,86 \\
\hline Estudo de Texto & 110 & 41,83 & 54 & 42,86 & 24 & 36,36 & 0 & 0,00 & 4 & 5,56 & 26 & 50,98 \\
\hline Seminário & 60 & 22,81 & 24 & 19,05 & 15 & 22,73 & 14 & 38,89 & 20 & 27,78 & 16 & 31,37 \\
\hline Discussão e Debate & 71 & 27,00 & 26 & 20,63 & 18 & 27,27 & 14 & 38,89 & 11 & 15,28 & 7 & 13,73 \\
\hline Caso de Estudo & 66 & 25,10 & 25 & 19,84 & 26 & 39,39 & 0 & 0,00 & 25 & 34,72 & 5 & 9,80 \\
\hline Ensino com pesquisa & 50 & 19,01 & 19 & 15,08 & 18 & 27,27 & 0 & 0,00 & 39 & 54,17 & 9 & 17,65 \\
\hline Aulas Práticas e em Laboratório & 42 & 15,97 & 8 & 6,35 & 5 & 7,58 & 10 & 27,78 & 26 & 36,11 & 8 & 15,69 \\
\hline Projeção de vídeos & 57 & 21,67 & 11 & 8,73 & 1 & 1,52 & 0 & 0,00 & 9 & 12,50 & 0 & 0,00 \\
\hline Ensino à Distância & 8 & 3,04 & 25 & 19,84 & 12 & 18,18 & 2 & 5,56 & 4 & 5,56 & 1 & 1,96 \\
\hline Produção Textual & 38 & 14,45 & 4 & 3,17 & 4 & 6,06 & 0 & 0,00 & 3 & 4,17 & 0 & 0,00 \\
\hline Explicações por parte do aluno & 4 & 1,52 & 12 & 9,52 & 10 & 15,15 & 0 & 0,00 & 6 & 8,33 & 2 & 3,92 \\
\hline Exposições e Visitas técnicas & 8 & 3,04 & 12 & 9,52 & 5 & 7,58 & 0 & 0,00 & 2 & 2,78 & 1 & 1,96 \\
\hline Estudo Dirigido & 7 & 2,66 & 1 & 0,79 & 0 & 0,00 & 0 & 0,00 & 2 & 2,78 & 4 & 7,84 \\
\hline Palestras & 3 & 1,14 & 0 & 0,00 & 1 & 1,52 & 0 & 0,00 & 7 & 9,72 & 0 & 0,00 \\
\hline Dinâmicas & 9 & 3,42 & 0 & 0,00 & 0 & 0,00 & 0 & 0,00 & 2 & 2,78 & 0 & 0,00 \\
\hline Ensino com projeto & 5 & 1,90 & 0 & 0,00 & 3 & 4,55 & 0 & 0,00 & 0 & 0,00 & 0 & 0,00 \\
\hline Dramatização & 2 & 0,76 & 0 & 0,00 & 1 & 1,52 & 0 & 0,00 & 4 & 5,56 & 0 & 0,00 \\
\hline Jogos de empresa & 2 & 0,76 & 0 & 0,00 & 0 & 0,00 & 0 & 0,00 & 5 & 6,94 & 0 & 0,00 \\
\hline Painel & 2 & 0,76 & 0 & 0,00 & 0 & 0,00 & 0 & 0,00 & 0 & 0,00 & 0 & 0,00 \\
\hline Júri simulado & 0 & 0,0 & 0 & 0,00 & 2 & 3,03 & 0 & 0,00 & 0 & 0,00 & 0 & 0,00 \\
\hline Estudo de Campo & 0 & 0,0 & 1 & 0,79 & 0 & 0,00 & 0 & 0,00 & 0 & 0,00 & 0 & 0,00 \\
\hline
\end{tabular}

Legenda: \% ${ }^{a}$ - Frequência relativa em relação ao total de planos de ensino por núcleo de conteúdo Fonte: dados da pesquisa.

Nos planos de ensino das disciplinas que compõem o núcleo de formação básica observa-se que, além das estratégias supracitadas, também obtiveram destaque as estratégias de estudo de texto $(41,83 \%)$, discussão e debate $(27 \%)$ e caso de estudo $(25,10 \%)$. Destaca-se que, comparativamente aos demais núcleos de conteúdo, este foi o que mais apresentou a estratégia de produção textual $(14,45 \%)$, tanto em termos de frequência relativa, quanto em termos de frequência absoluta. Atribui-se tal fato à existência das disciplinas: português instrumental e comunicação acadêmica e empresarial, que apresentam atividades relacionadas ao desenvolvimento da capacidade de escrever dos acadêmicos.

Em relação aos planos de ensino das disciplinas da área financeira, observa-se que as estratégias mais recorrentes, após aulas expositivas e exercícios, foram estudo de texto $(42,86 \%)$, discussão e debate $(20,63 \%)$, caso de estudo $(19,84 \%)$, ensino a distância $(19,84 \%)$ 
e seminário (19,05\%). Relativamente à estratégia de ensino à distância, pode-se perceber que é na área financeira que ela é mais recorrente, aparecendo em 25 dos 126 planos desta área.

Nos planos de ensino da área gerencial destacam-se as estratégias de exercícios $(83,33 \%)$, aula expositiva dialogada $(56,06 \%)$, aula expositiva $(43,94 \%)$, caso de estudo $(39,39 \%)$, estudo de texto $(36,36 \%)$, ensino com pesquisa $(27,27 \%)$ e discussão e debate (27,27\%). Tais resultados são convergentes aos achados de Nganga et al. (2013) que também encontraram altos índices de utilização destas estratégias, por docentes das disciplinas de Contabilidade de Custos e Contabilidade Gerencial, respectivamente. Salienta-se que tais disciplinas pertencem à área gerencial, demonstrando assim consonância entre os resultados aqui encontrados e as pesquisas mencionadas.

Destaca-se aqui que a estratégia de explicação por parte do aluno, em termos percentuais, foi mais frequente do que se observa nas demais áreas e núcleos de conteúdo, ao passo que a estratégia de exposições e visitas técnicas, apresentou pouca representatividade quando comparada às demais áreas, divergindo dos achados de Leal e Borges (2014), em que tal estratégia foi predominante nas disciplinas da área gerencial.

No que concerne às disciplinas da área pública/tributária, destaca-se que dentre todas as 23 estratégias observadas nos planos de ensino, apenas seis delas são utilizadas pelos professores que lecionam as disciplinas que compõe esta área. Isso denota que os professores das disciplinas da área pública/tributária pouco variam suas estratégias, ficando limitados a seminário (38,89\%), discussão e debate $(38,89 \%)$, aulas práticas e em laboratório $(27,78 \%)$ e ensino à distância (5,56\%), além das já supracitadas aulas expositivas $(91,67 \%)$, exercícios $(80,56 \%)$ e aulas expositivas dialogadas $(8,33 \%)$.

Esta constatação é concorde com os achados de Leal e Borges (2014), em que se pôde observar que as disciplinas da área pública/tributária foram as que apresentaram menos tipos de estratégias. Estes resultados atentam para a necessidade de se ponderar sobre as estratégias encontradas na literatura e sua aplicabilidade nas disciplinas relacionadas com o ensino da contabilidade tributária e pública. Ou seja, será que as estratégias não se adequam ao conteúdo, ou será que são os professores que não buscam por novas formas de trabalhar a matéria proposta nas ementas? É uma reflexão a se fazer.

Nos planos de ensinos do grupo "outras áreas", que contemplou disciplinas como auditoria, mercado de capitais, perícia contábil, jogos de empresas, prática contábil e sistemas contábeis, observa-se que as estratégias mais recorrentes foram ensino com pesquisa 


\section{ESTRATÉGIAS APLICADAS NO ENSINO DA CONTABILIDADE: EVIDÊNCIAS DOS PLANOS DE ENSINO DE UMA UNIVERSIDADE PÚBLICA \\ DOI: http://dx.doi.org/10.5007/1983-4535.2019v12n2p24}

$(54,17 \%)$, aulas práticas e em laboratório $(36,11 \%)$ e caso de estudo $(34,72 \%)$. Nota-se que, em termos percentuais, esta foi a área em que a estratégia aulas práticas e em laboratório foi mais recorrente. Atribui-se isso ao fato de que as disciplinas de prática contábil e sistemas contábeis normalmente envolvem atividades relacionadas ao uso do computador e de softwares contábeis.

Por fim, nos planos de ensino das disciplinas que compõe o núcleo de formação teórico-prática, observa-se que há maior predominância das estratégias tradicionais tais como estudo de texto $(50,98 \%)$ e seminário $(31,37 \%)$, além de exercícios $(90,20 \%)$, aulas expositivas dialogadas $(56,86 \%)$ e aulas expositivas $(43,14 \%)$, como exposto anteriormente.

De modo geral pode-se inferir que os planos de ensino das disciplinas do núcleo de formação básica foram os que apresentaram estratégias mais variadas, contemplando 21 estratégias das 23 observadas, seguido pelas disciplinas da área gerencial, com um total de 18 estratégias. Contrapondo tais achados encontram-se as disciplinas da área pública/ tributária, que apresentaram o menor número de estratégias, contemplando apenas seis das 23 estratégias observadas no estudo.

Posteriormente à analise das estratégias por núcleo de conteúdo procedeu-se a análise por titulação do professor. Para tanto foram buscadas as titulações de cada professor em seu currículo Lattes, sendo que foram identificados 45 planos de ensino de disciplinas ministradas por professores com graduação, 114 com especialização, 425 com mestrado e 30 com doutorado, conforme pode-se observar na Tabela 6.

Como observa-se na Tabela 5, os professores que possuem apenas graduação possuem preferência por aulas expositivas dialogadas $(71,11 \%)$ em detrimento de aulas expositivas $(28,89 \%)$. Dentre as estratégias mais recorrentes encontram-se, também, a utilização de exercícios (91,11\%), estudo de texto (42,22\%) e aulas práticas e em laboratório (20\%). Destaca-se que nenhum dos professores com graduação utilizou as estratégias de exposições e visitas técnicas, palestras, dinâmicas, ensino com projeto, dramatização, jogos de empresa, painel, júri simulado e estudo de campo, demostrando, assim, que estes professores se limitam a estratégias de ensino mais tradicionais.

Dentre os professores com especialização observa-se que há maior predominância da aula expositiva $(74,56 \%)$ em comparação com a aula expositiva dialogada $(25,44 \%)$. Observa-se, também, uma maior frequência na utilização de exercícios (74,56\%), caso de estudos $(34,21 \%)$, estudo de texto $(33,33 \%)$, ensino com pesquisa $(32,46 \%)$ e seminário 
$(31,58 \%)$. Nota-se que, dentre os professores com especialização, houve maior utilização das estratégias de ensino em relação àqueles com graduação, sendo identificada a utilização de 18 estratégias entre as 23 observadas.

Tabela 6 Estratégias por Titulação do Professor

\begin{tabular}{l|c|c|c|c|c|c|c|c}
\hline Planos de Ensino & \multicolumn{2}{|c|}{$\mathbf{4 5}$} & \multicolumn{2}{|c|}{$\mathbf{1 1 4}$} & \multicolumn{2}{|c|}{$\mathbf{4 2 5}$} & \multicolumn{2}{|c}{30} \\
\hline \multirow{2}{*}{ Estratégias } & \multicolumn{2}{|c|}{ Graduação } & Especialização & \multicolumn{2}{|c|}{ Mestrado } & \multicolumn{2}{|c}{ Doutorado } \\
\cline { 2 - 8 } & $\mathrm{Q}$ & $\%^{\mathrm{a}}$ & $\mathrm{Q}$ & $\%^{\mathrm{a}}$ & $\mathrm{Q}$ & $\%^{\mathrm{a}}$ & $\mathrm{Q}$ & $\%^{\mathrm{a}}$ \\
\hline Exercícios & 41 & $91,11 \%$ & 85 & $74,56 \%$ & 298 & $70,12 \%$ & 23 & $76,67 \%$ \\
Aula Expositiva & 13 & $28,89 \%$ & 85 & $74,56 \%$ & 213 & $50,12 \%$ & 13 & $43,33 \%$ \\
Aula Expositiva Dialogada & 32 & $71,11 \%$ & 29 & $25,44 \%$ & 212 & $49,88 \%$ & 17 & $56,67 \%$ \\
Estudo de Texto & 19 & $42,22 \%$ & 38 & $33,33 \%$ & 156 & $36,71 \%$ & 5 & $16,67 \%$ \\
Seminário & 5 & $11,11 \%$ & 36 & $31,58 \%$ & 104 & $24,47 \%$ & 4 & $13,33 \%$ \\
Discussão e Debate & 6 & $13,33 \%$ & 22 & $19,30 \%$ & 109 & $25,65 \%$ & 10 & $33,33 \%$ \\
Caso de Estudo & 1 & $2,22 \%$ & 39 & $34,21 \%$ & 107 & $25,18 \%$ & 0 & $0,00 \%$ \\
Ensino com Pesquisa & 3 & $6,67 \%$ & 37 & $32,46 \%$ & 88 & $20,71 \%$ & 7 & $23,33 \%$ \\
Aulas Práticas e em Laboratório & 9 & $20,00 \%$ & 29 & $25,44 \%$ & 57 & $13,41 \%$ & 4 & $13,33 \%$ \\
Projeção de vídeos & 2 & $4,44 \%$ & 18 & $15,79 \%$ & 56 & $13,18 \%$ & 2 & $6,67 \%$ \\
Ensino à Distância & 1 & $2,22 \%$ & 2 & $1,75 \%$ & 44 & $10,35 \%$ & 5 & $16,67 \%$ \\
Produção Textual & 1 & $2,22 \%$ & 0 & $0,00 \%$ & 43 & $10,12 \%$ & 5 & $16,67 \%$ \\
Explicações por parte do aluno & 8 & $17,78 \%$ & 1 & $0,88 \%$ & 25 & $5,88 \%$ & 0 & $0,00 \%$ \\
Exposições e Visitas técnicas & 0 & $0,00 \%$ & 0 & $0,00 \%$ & 25 & $5,88 \%$ & 3 & $10,00 \%$ \\
Estudo Dirigido & 7 & $15,56 \%$ & 7 & $6,14 \%$ & 0 & $0,00 \%$ & 0 & $0,00 \%$ \\
Palestras & 0 & $0,00 \%$ & 4 & $3,51 \%$ & 5 & $1,18 \%$ & 2 & $6,67 \%$ \\
Dinâmicas & 0 & $0,00 \%$ & 4 & $3,51 \%$ & 7 & $1,65 \%$ & 0 & $0,00 \%$ \\
Ensino com projeto & 0 & $0,00 \%$ & 0 & $0,00 \%$ & 7 & $1,65 \%$ & 1 & $3,33 \%$ \\
Dramatização & 0 & $0,00 \%$ & 1 & $0,88 \%$ & 5 & $1,18 \%$ & 1 & $3,33 \%$ \\
Jogos de empresa & 0 & $0,00 \%$ & 4 & $3,51 \%$ & 1 & $0,24 \%$ & 2 & $6,67 \%$ \\
Painel & 0 & $0,00 \%$ & 2 & $1,75 \%$ & 0 & $0,00 \%$ & 0 & $0,00 \%$ \\
Júri simulado & 0 & $0,00 \%$ & 0 & $0,00 \%$ & 2 & $0,47 \%$ & 0 & $0,00 \%$ \\
Estudo de Campo & 0 & $0,00 \%$ & 0 & $0,00 \%$ & 1 & $1,52 \%$ & 0 & $0,00 \%$ \\
\hline
\end{tabular}

Legenda: $\%{ }^{\mathrm{a}}$ - Frequência relativa em relação ao total de planos de ensino por titulação Fonte: dados da pesquisa.

No grupo de planos de ensino das disciplinas lecionadas por professores que possuem mestrado observa-se que o número de planos com aula expositiva dialogada é muito próximo ao número de planos com aula expositiva, demonstrando assim equilíbrio entre essas duas estratégias neste grupo. Destacam-se também as estratégias de exercícios (70,12\%), estudo de texto $(36,71 \%)$ e discussão e debate $(25,65 \%)$. De modo geral verifica-se que este é o grupo que mais apresentou estratégias variadas, 21 estratégias dentre as 23 identificadas.

Ao observar-se o grupo de planos de ensino das disciplinas lecionadas por professores com doutorado observa-se, entretanto, que a quantidade de estratégias diversificadas é inferior ao número encontrado entre os professores com especialização e com mestrado (16 dentre 23 
estratégias). Entre as estratégias mais recorrentes neste grupo encontram-se a aula expositiva dialogada (56,67\%), aula expositiva (43,33\%), exercícios $(76,67 \%)$ e discussão e debate $(33,33 \%)$.

\section{CONCLUSÃO}

Esta pesquisa teve como objetivo identificar as estratégias de ensino que são aplicadas com maior frequência nas disciplinas do curso de graduação em Ciências Contábeis de uma Universidade Catarinense. Trata-se de uma pesquisa descritiva, com abordagem quantitativa realizada por meio da análise documental de 614 planos de ensino da instituição em questão. Os planos de ensino analisados se encontram disponíveis na página institucional da Universidade e são de livre acesso a todos. Uma etapa adicional da coleta de dados contemplou a pesquisa ao currículo Lattes dos professores da instituição a fim de identificar sua titulação.

A análise dos dados revelou que há maior utilização de estratégias de ensino tradicionais, consonante aos achados de outras pesquisas sobre estratégias de ensino (TEODORO et al., 2011; MIRANDA, LEAL \& CASA NOVA, 2012; PASSOS \& MARTINS, 2012; MAZZIONE, 2013; LEAL \& BORGES, 2014; SILVA et al., 2014). Dentre as estratégias identificadas, observou-se que há maior predominância da aula expositiva em relação à aula expositiva dialogada, divergindo dos achados de Leal e Cornachione Jr. (2006). Outras estratégias recorrentes foram exercícios, estudo de texto, seminário, discussão e debate e caso de estudo. Destaca-se que, algumas estratégias não tradicionais identificadas na literatura não foram encontradas nos planos de ensino analisados, tais como grupos de verbalização e observação, aprendizagem baseada em problema, simpósio, aprendizagem experiencial/estágio, diálogos sucessivos e formulação de questões.

Em relação à análise por núcleo de conteúdo da disciplina, observou-se que a aplicação de exercícios é uma estratégia recorrente a todos os núcleos de conteúdo. Em relação à aula expositiva, observou-se que a modalidade dialogada predominou em três dos seis núcleos analisados. Pôde-se constatar, também, que os núcleos que apresentaram o maior número de estratégias diversificadas foram o núcleo de formação básica e o núcleo de formação profissional, na área gerencial, ao passo que a área pública/tributária apresentou o menor número de estratégias diversificadas, limitando-se às estratégias tradicionais. 


\section{ESTRATÉGIAS APLICADAS NO ENSINO DA CONTABILIDADE: EVIDÊNCIAS DOS PLANOS DE ENSINO DE UMA UNIVERSIDADE PÚBLICA \\ DOI: http://dx.doi.org/10.5007/1983-4535.2019v12n2p24}

Relativamente aos resultados da análise por titulação do professor, contatou-se que professores com doutorado apresentaram menor diversificação de estratégias do que aqueles com especialização e mestrado.

Deve-se destacar que os resultados aqui encontrados se limitam à amostra estudada, não permitindo, portanto, generalizações. Destacam-se, ainda, como limitações da pesquisa os documentos utilizados na análise, neste caso os planos de ensino, visto que não há garantia de que o que foi declarado no plano pelo professor foi efetivamente cumprido em sala de aula. Neste sentido, Masetto (2003) comenta que, muitas vezes, o plano de ensino serve apenas para atender questões burocráticas, sendo que o professor apenas se limita a alterar as datas, utilizando o mesmo plano de ensino por diversos semestres.

Em função disso, sugere-se que em futuras pesquisas sejam confrontadas as estratégias identificadas nos planos de ensino com a percepção dos discentes acerca das estratégias mais utilizadas no ensino de Ciências Contábeis. Também pode-se investigar os procedimentos e critérios adotados pelos docentes na escolha das estratégias de ensino, bem como a relação entre os objetivos educacionais e as estratégias escolhidas.

\section{REFERÊNCIAS}

ANASTASIOU, L. G. C.; ALVES, L. P. Estratégias de Ensinagem. In: ANASTASIOU, L. G. C.; ALVES, L. P. (Org.). Processos de Ensinagem na Universidade: Pressupostos para as estratégias de trabalho em aula. 3. ed. Joinville : UNIVILLE, 2004.

BALZAN, N. C. Sete asserções inaceitáveis sobre inovação educacional. In: GARCIA, W. E. (Coord.). Inovação educacional no Brasil: problemas e perspectivas. 3. ed. Campinas : Autores Associados, 1995.

BORDENAVE, J. D.; PEREIRA, A. M. Estratégias de ensino-aprendizagem. 24 ed. Petrópolis: Vozes, 2002.

GIL, Antonio Carlos. Metodologia do ensino superior. 4. ed. São Paulo : Atlas, 2005.

GIL, A. C. Didática do ensino superior. 1. ed. São Paulo: Atlas, 2006.

GODOY, A. S. Revendo a aula expositiva. In: MOREIRA, D. A. (Org.). Didática do ensino superior: técnicas e tendências. São Paulo: Pioneira, 1997.

GRILLO, M. C.; FREITAS, A. L. S. Estudo de texto. In: GRILLO, M. C. et al. (Org.). A gestão da aula universitária na PUCRS. Porto Alegre: EDIPUCRS, 2008. 
HERNANDES, D. C. R.; PELEIAS, I. R.; BARNALHO, V. F. O professor de contabilidade: habilidades e competências. In: PELEIAS, I. R. (org.) Didática do ensino da contabilidade: aplicável a outros cursos superiores. São Paulo: Saraiva, 2006.

LEAL, R. B. Planejamento de ensino: peculiaridades significativas. Revista Iberoamericana de Educación, v. 37, n. 3, p. 1-6, 2005.

LEAL, E. A.; BORGES, A. V. S. Estratégias e métodos aplicados no ensino da Contabilidade: uma análise dos planos de ensino do Curso de Ciências Contábeis de uma instituição pública brasileira. In: Congresso ANPCONT, 8, 2014, Rio de Janeiro. Anais... Rio de Janeiro: ANPCONT, 2014.

LEAL, D. T. B.; CORNACHIONE JR, E. A aula expositiva no ensino da contabilidade. Contabilidade vista \& revista, v. 17, n. 3, p. 91-113, 2006.

LOPES, A. O. Aula expositiva: superando o tradicional. In: VEIGA, I. P. A. (Org.). Técnicas de Ensino: Por que não? Campinas: Papirus, 2003.

LUCKESI, Cipriano. Filosofia da educação.3. ed. São Paulo : Cortez, 2011.

MACÊDO, L. C. B. et al. Avaliação dos conteúdos das disciplinas relacionadas à área gerencial: um estudo em universidades públicas estaduais no brasil. Registro Contábil, v. 6, n. 1, p. 52-70, 2014.

MALUSÁ, S. Investigação sobre a atualização docente no ensino superior. In: MALUSÁ, S.; FELTRAN, R. C. S; (orgs.) A prática da docência universitária. São Paulo: Factash Editora, 2003.

MARION, J. C.; MARION, A. L. C. Metodologias de ensino na área de negócios: para cursos de administração, gestão, contabilidade e MBA. São Paulo: Atlas, 2006.

MARTINS, J. P. Didática geral: fundamentos, planejamento, metodologia, avaliação. São Paulo: Atlas, 1993.

MASETTO, M. T. Competência pedagógica do professor universitário. São Paulo: Summus, 2003.

MAZZIONI, S. As estratégias utilizadas no processo de ensino-aprendizagem: Concepções de alunos e professores de Ciências Contábeis. Revista Eletrônica de Administração e Turismo-ReAT, v. 2, n. 1, p. 93-109, 2013.

MIRANDA, G. J.; CASA NOVA, S. P. C.; CORNACHIONE JR, E. B. The accounting education gap in Brazil. China - USA Business Review, v. 12, n. 4, p. 361-372, abr. 2013.

MIRANDA, G. J.; LEAL, E. A.; CASA NOVA, S. P. de C. Técnicas de ensino aplicadas à contabilidade: existe uma receita? In: COIMBRA, C. L. (Org). Didática para o ensino nas áreas de administração e ciências contábeis. São Paulo: Atlas, 2012. 
NERICI, I. G. Metodologia do ensino: uma introdução. São Paulo: Atlas, 1990.

NERICI, I. G. Introdução à Didática Geral. Rio de Janeiro: Científica, 1997.

NGANGA C. S. N.; et al. Estratégias e técnicas aplicadas no ensino da contabilidade gerencial: um estudo com docentes do curso de ciências contábeis. In: Encontro de Ensino e Pesquisa em Administração e Contabilidade, 4, Brasília. Anais... Brasília, 2013, CD-ROM.

OLIVEIRA, A. J. et al. Estilos de aprendizagem e estratégias ludopedagógicas: percepções no ensino da contabilidade. Advances in Scientific and Applied Accounting. São Paulo, v.6, n.2, p. 236-262, 2013.

PALMA, D. A.; QUEIROZ, M. R. B. A gestão do currículo do curso superior de Ciências Contábeis. In: PELEIAS, I. R. (org.) Didática do ensino da contabilidade: aplicável a outros cursos superiores. São Paulo: Saraiva, 2006.

PASSOS, I. C.; MARTINS, G. A. Métodos de sucesso no ensino da Contabilidade. In: COIMBRA, C. L. (Org). Didática para o ensino nas áreas de administração e ciências contábeis. São Paulo: Atlas, 2012.

PETRUCCI, V. B. C.; BATISTON, R. R. Estratégias de ensino e avaliação de aprendizagem em contabilidade. In: PELEIAS, I. R. (org.) Didática do ensino da contabilidade: aplicável a outros cursos superiores. São Paulo: Saraiva, 2006.

SILVA, U. B. et al. Concepções pedagógicas e mudanças nas práticas contábeis: um estudo sobre o modelo educacional adotado em uma universidade pública e a formação críticoreflexiva do contador. Revista de Contabilidade e Controladoria, v. 6, n. 2, p. 54-66, maio/ago. 2014.

TEODORO, J. D. et al. Estratégias de Ensino-Aprendizagem: Estudo Comparativo no Ensino Superior nas Áreas de Educação e Ciências Contábeis. In: Encontro de Ensino e Pesquisa em Administração e Contabilidade, 3, 2011, João Pessoa. Anais... João Pessoa: ANPAD, 2011. 